\title{
Population structure and genome-wide association analysis for frost tolerance in oat using continuous SNP array signal intensity ratios
}

\author{
Giorgio Tumino $^{1,2} \cdot$ Roeland E. Voorrips $^{2} \cdot$ Fulvia Rizza $^{1} \cdot$ Franz W. Badeck $^{1}$. \\ Caterina Morcia $^{1} \cdot$ Roberta Ghizzoni $^{1} \cdot$ Christoph U. Germeier $^{4} \cdot$ Maria-João Paulo $^{3}$. \\ Valeria Terzi ${ }^{1} \cdot$ Marinus J. M. Smulders $^{2}$
}

Received: 26 March 2016 / Accepted: 21 May 2016 / Published online: 18 June 2016

(C) The Author(s) 2016. This article is published with open access at Springerlink.com

\begin{abstract}
Key message Infinium SNP data analysed as continuous intensity ratios enabled associating genotypic and phenotypic data from heterogeneous oat samples, showing that association mapping for frost tolerance is a feasible option.

Abstract Oat is sensitive to freezing temperatures, which restricts the cultivation of fall-sown or winter oats to regions with milder winters. Fall-sown oats have a longer growth cycle, mature earlier, and have a higher productivity than spring-sown oats, therefore improving frost tolerance is an important goal in oat breeding. Our aim was to test the effectiveness of a Genome-Wide Association Study (GWAS) for mapping QTLs related to frost tolerance, using an approach that tolerates continuously distributed signals from SNPs in bulked samples from heterogeneous accessions. A collection of 138 European oat accessions,
\end{abstract}

Communicated by X. Qi.

Electronic supplementary material The online version of this article (doi:10.1007/s00122-016-2734-y) contains supplementary material, which is available to authorized users.

Giorgio Tumino

giorgiotumino@hotmail.it

1 Council for Agricultural Research and Economics, Genomics Research Centre, Via San Protaso 302, 29017 Fiorenzuola d'Arda, PC, Italy

2 Wageningen UR Plant Breeding, Droevendaalsesteeg 1, NL-6708 PB Wageningen, The Netherlands

3 Biometris, Wageningen UR, Droevendaalsesteeg 1, NL-6708 PB Wageningen, The Netherlands

4 Julius Kühn Institut, Federal Research Centre for Cultivated Plants, Institute for Breeding Research on Agricultural Crops, 06484 Quedlinburg, Germany including landraces, old and modern varieties from 27 countries was genotyped using the Infinium 6K SNP array. The SNP data were analyzed as continuous intensity ratios, rather than converting them into discrete values by genotype calling. PCA and Ward's clustering of genetic similarities revealed the presence of two main groups of accessions, which roughly corresponded to Continental Europe and Mediterranean/Atlantic Europe, although a total of eight subgroups can be distinguished. The accessions were phenotyped for frost tolerance under controlled conditions by measuring fluorescence quantum yield of photosystem II after a freezing stress. GWAS were performed by a linear mixed model approach, comparing different corrections for population structure. All models detected three robust QTLs, two of which co-mapped with QTLs identified earlier in bi-parental mapping populations. The approach used in the present work shows that SNP array data of heterogeneous hexaploid oat samples can be successfully used to determine genetic similarities and to map associations to quantitative phenotypic traits.

\section{Introduction}

Hexaploid oat (Avena sativa L.) is an important crop grown on nearly 10 million hectares worldwide (FAOSTAT 2015) mostly in temperate regions in a wide range of environmental conditions. Gene banks preserve about 80,000 accessions of cultivated oats and more than 20,000 wild oats. This germplasm can be considered a reservoir of potentially useful genes, to be exploited in pre-breeding and breeding programs (Lipman et al. 2005). An important trait for oat, to which much (pre-) breeding is devoted, is tolerance to frost. Among winter cereals, oat is in fact the most frost sensitive and its insufficient level of winter hardiness 
is one of the most important factors limiting the cultivation of winter oat in cold areas. In most of Europe therefore spring-sown oats are grown, but where winters are mildlike in the UK and in Southern Europe-winter oats, sown during the autumn, are preferred. Winter oats have a long growth cycle and early maturity, and give higher yields.

Winter hardiness can be defined as the ability to survive throughout the winter. Because of the wide range of stressful conditions that a plant may experience during the cold season, winter hardiness is a complex trait. Freezing temperature is the most relevant stress factor, although other stress situations, such as anoxia due to excess of water or to ice encasement, photoinhibition and mold infection may also occur (Stanca et al. 2003). The ability of overwintering plants to withstand cold is mainly based on an adaptive response, known as cold acclimation or hardening, activated during growth at low non-freezing temperatures. Frost tolerance-a complex trait influenced by Genotype by Environment (GxE) interaction-can be assessed through field evaluation methods, but these depend on the occurrence of the proper natural conditions to satisfactorily differentiate genotypes. Alternatively, artificial freezing tests have been used that measure the percentage of post-stress survival, LT50 (temperature at which $50 \%$ of the population is killed), integrity of cell membranes after freezing (Rizza et al. 1994) or the chlorophyll $F_{\mathrm{v}} / F_{\mathrm{m}}$ ratio, that is the maximum quantum yield of the PSII photochemistry after freezing (Rizza et al. 2001).

Vernalization can be defined as the induction of the competence to flower by a prolonged exposure to winter cold. Vrn-l is the main locus responsible for vernalization sensitivity in cereals. In the currently accepted model for wheat and barley $V r n-2$ acts as a repressor of $F t-1$ (Vrn-3), which is an orthologue to the Arabidopsis Flowering Locus $T$ responsible for flower initiation (Yan et al. 2006). During vernalization $V r n-1$ is progressively induced repressing $V r n-2$ and allowing induction of $F t-l$ (Yan et al. 2004; Trevaskis et al. 2006; Hemming et al. 2008; Chen and Dubcovsky 2012). Depending on vernalization requirement, sensitivity to photoperiod and frost tolerance the oat germplasm grown in temperate climates is usually divided into spring, winter and facultative types. Spring types tend to flower quickly, do not require vernalization and are often insensitive to photoperiod. Winter types show a strong vernalization requirement and are sensitive to short days. Facultative types do not require vernalization but show levels of frost tolerance similar to winter types. In barley the difference between spring, winter and facultative types has been mostly explained by molecular variation in $\mathrm{Vrn}-\mathrm{HI}$ and $\mathrm{Vrn}-\mathrm{H} 2$. A dominant allele of $\mathrm{Vrn}-\mathrm{Hl}$ determines the spring habit, while a homozygous recessive combination correlates with winter and facultative types (von Zitzewitz et al. 2005; Szucs et al. 2007). Allelic variation at Vrn-H2 has been found to be responsible for the differences in vernalization requirement observed between winter and facultative types (Szucs et al. 2007). However, the distinction among the oat types does not appear so clear as in barley, since oat winter types sown in late spring are often able to flower and produce viable seeds (as observed in this study). In tetraploid wheat, Vrn-1 null mutants were shown to flower very late but to produce normal flowers and seeds, suggesting that $V r n-1$ is not essential for wheat flowering and alternative flowering genes may exist (Chen and Dubcovsky 2012). In addition, an alternative pathway of flower initiation via the barley gene HvFT3 was proposed by Casao et al. (2011).

Frost Resistance-1 (Fr-1/Vrn-1) and Frost Resistance-2 $(\mathrm{Fr}-2)$ are the main QTLs for frost tolerance in Triticeae and were mapped on the homoeologous group 5 chromosomes (Francia et al. 2004; Galiba et al. 1995). Both in barley and in wheat $\mathrm{Fr}-1$ co-segregates with $\mathrm{Vrn}-1$; the frost tolerance attributed to $\mathrm{Fr}-\mathrm{I}$ is therefore most likely a pleiotropic effect of Vrn-1 (Limin and Fowler 2006; Dhillon et al. 2010). The locus $\mathrm{Fr}$-2 includes a cluster of more than $10 \mathrm{C}-$ Repeat Binding Factor (CBF) transcription factors (Francia et al. 2007), which are known as regulators of COR (Cold-regulated) gene expression, playing a role in protection from frost damage (Park et al. 2015). In barley, an increase in copy number of $H v C B F 2$ and $H v C B F 4$ was suggested to be the causal polymorphism determining frost tolerance (Knox et al. 2010), although allelic variation at $\mathrm{HvCBF} 14$ was found statistically significant as well (Fricano et al. 2009). Recently, Zhu et al. (2014) showed that bread wheat frost tolerance is significantly affected by the interaction between the locus $\mathrm{Vrn}-\mathrm{Al}$ and $\mathrm{Fr}$-A2. Two main allelic variants ( $\mathrm{S}$ and $\mathrm{T}$ ) were identified for $\mathrm{Fr}$-A2, based on sequence polymorphisms in the region $C B F-A 12 / C B F$ $A 15$ and copy number variation of $C B F-A 14$. An increased copy number of $V r n-A l$ enhanced frost tolerance but only when the T allele was present at the $F r-A 2$ locus (Zhu et al. 2014). Mutations in the homoeologous genes $V r n-B 1$ and Vrn-Dl had a weaker effect (Zhu et al. 2014). In barley, genome-wide association study (GWAS) was successfully used for identifying main QTLs affecting frost tolerance (von Zitzewitz et al. 2011; Visioni et al. 2013; Tondelli et al. 2014). Another QTL affecting frost tolerance ( $F r-H 3)$ was identified on the barley chromosome $1 \mathrm{H}$ accounting for $48 \%$ of the phenotypic variation in two double haploid populations originating from winter and facultative types (Fisk et al. 2013).

Knowledge on molecular pathways underlying frost tolerance, sensitivity to photoperiod and vernalization in oat is still poor. To this date, the main studies on oat winter hardiness were based on linkage mapping in bi-parental populations, using a limited number of AFLP, SSR or DArT markers. Recently, the Infinium 6K oat SNP array was developed 
(Tinker et al. 2014; Oliver et al. 2013). Moreover, a dense hexaploid oat consensus map based on 12 bi-parental populations, mostly originating from North American spring varieties, is now available (Chaffin et al. 2016). The availability of these tools together with new genetic populations-such as the wide European germplasm collection established by the AVEQ project (http://aveq.jki.bund.de/aveq) —opens new perspectives to the study of adaptive traits in oats.

In the present work we genotyped a diverse collection of European oats, including modern, old varieties and landraces, with potentially different degrees of sample heterogeneity. The approach we used is based on the analysis of SNP array signals as continuous intensity ratios, skipping the genotype calling step. This approach tolerates sample heterogeneity and avoids the effort and the potential (over-) interpretation errors involved in genotype calling, which is particularly challenging in allopolyploid genomes. The objectives of the work were: (1) to study genetic diversity in European oat germplasm, (2) to show the feasibility of GWAS based on continuous SNP signal ratios in a collection including heterogeneous samples for simple traits such as lemma color and hullessness, whose phenotypic variation is explained by few major genes, (3) to use GWAS and chlorophyll fluorescence data for identifying QTLs affecting frost tolerance in oat.

\section{Materials and methods}

\section{Plant materials and DNA extraction}

A collection of 138 oat accessions, originating from 27 European countries, was analyzed in the present study. It contains a few diploid $A$. strigosa accessions and 133 hexaploid $A$. sativa accessions, including landraces and cultivars used for spring and winter sowing and representing about 100 years of European oat breeding history. Further information about genebank holder, taxonomy, country of origin, growth habit and year of registration can be found in Online Resource 1.

To take into account intra-varietal genetic variability, young leaves from 10 plants for each accession were pooled and genomic DNA was extracted using a CTAB solution followed by chloroform extraction.

\section{Genotyping and SNP quality filtering}

About 5000 SNP markers were assayed using the Infinium 6K Oat array (Tinker et al. 2014). Array fluorescence signals were imported and normalized in the GenomeStudio software (Illumina Inc., San Diego, CA) and then exported for the following analyses. Genotype calling in allopolyploids can be complicated, e.g., in allopolyploid wheat because of, amongst others, low signal intensity and variable hybridization of homoeologous loci (Wang et al. 2014). We used hybridization intensities as continuous scores, instead of separating the signals in clusters for genotype calling, i.e., calculating discrete variables. Continuous variables allowed us to include in the mapping population also landraces and old local varieties, which are expected to have some degree of genetic heterogeneity. For each marker, we calculated intensity ratios according to the formula $\mathrm{X} /(\mathrm{X}+\mathrm{Y})$, where $\mathrm{X}$ and $\mathrm{Y}$ are normalized hybridization intensities for alleles $\mathrm{A}$ and $\mathrm{B}$. Total intensity signals $(R)$ and intensity ratios were used for marker and sample quality checking. Single data points with extreme $R$ values $(R<0.25$ or $R>2.5)$ were set as missing and markers with more than $25 \%$ missing values were excluded. Variance of intensity ratios per marker was used to remove uninformative markers (variance $<0.001$ ). After these filters, remaining missing values were replaced by the mean ratio per marker. Moreover, seven samples were removed, since the intensity ratio frequency distribution per sample indicated high levels of heterogeneity. These quality checks resulted in a dataset of 131 samples, including five diploid A. strigosa samples, and 3567 SNPs.

\section{Field trials phenotypic evaluation}

The mapping population-containing 126 hexaploid samples (five diploid A. strigosa samples were excluded)—was divided into two sets, hereafter referred as AVEQ08 and AVEQ09 containing 75 and 62 accessions, respectively, which were evaluated in eight European locations (France, Italy, Estonia, Czech Republic, Poland, Bulgaria, Romania and Germany) either in 2008 (AVEQ08) or in 2009 (AVEQ09). Eleven accessions were included in both sets as standard cultivars. The two sets were spring-sown in randomized block experiments and were phenotyped for hull percentage and days to heading. In addition, lemma colour was evaluated in the Fiorenzuola d'Arda (Italy) field trials for both populations, using the standard 1-6 scale (white, yellow, grey, red, brown, and black).

\section{Growth chamber frost tolerance evaluation}

The degree of leaf damage after exposure to freezing temperatures was evaluated in growth chamber experiments using chlorophyll fluorescence measurements. For each population five experiments were carried out. Seedlings were grown for 1 week at $20^{\circ} \mathrm{C} 8 \mathrm{~h}$ light, $15{ }^{\circ} \mathrm{C} 16 \mathrm{~h}$ dark. First-leaf stage plants were cold-hardened for 3 or 4 weeks and then subjected to a gradual lowering of temperature for freezing treatment. Two different hardening and freezing temperatures were used, to simulate optimal and sub-optimal acclimation conditions: a 4 week acclimation period at 
$3{ }^{\circ} \mathrm{C}, 8 \mathrm{~h}$ light, $1^{\circ} \mathrm{C}, 16 \mathrm{~h}$ dark, with a freezing treatment of $24 \mathrm{~h}$ at $-11 /-12^{\circ} \mathrm{C}$, for three out of the five experiments; and a 3 weeks period at $12{ }^{\circ} \mathrm{C} 8 \mathrm{~h}$ light, $7{ }^{\circ} \mathrm{C} 16 \mathrm{~h}$ dark, followed by a freezing treatment of $24 \mathrm{~h}$ at $-6 /-7^{\circ} \mathrm{C}$, for two experiments. After the stress period the temperature was gradually increased up to $1{ }^{\circ} \mathrm{C}$ with subsequent recovery at $20 / 15^{\circ} \mathrm{C}$. The experimental design was a randomized complete block design with cultivation trays as blocks (each tray containing all accessions). $F_{\mathrm{v}} / F_{\mathrm{m}}$ measurements were performed before, immediately after and $24 \mathrm{~h}$ after the stress period, using a pulse amplitude-modulated fluorometer (PAM 2000, Walz, Effeltrich, Germany), as described in Rizza et al. (2001). The measure before the stress period was used as a control.

\section{Data analysis}

Population structure was investigated by Ward's hierarchical clustering and Principal Component Analysis (PCA) of the marker signal ratios. Ward's clustering was performed using the algorithm implemented in the hclust function of the R package stats (R Core Team 2014), based on a matrix of pairwise Euclidean distances. PCA was based on a correlation matrix between hybridization ratios and were conducted in $\mathrm{R}$ by the function prcomp (package stats). Genetic variation within and between the identified clusters was tested by Analysis of Molecular Variance (Excoffier et al. 1992) using the function amova in the R package pegas (Paradis 2010).

Phenotypic data for hull percentage and days to heading were analyzed by multifactorial analysis of variance (ANOVA), including accession and environment as fixed factors. Accession adjusted values were used to perform association mapping. Chlorophyll $F_{\mathrm{v}} / F_{\mathrm{m}}$ data, ranging from 0 to 0.77 , were bimodally distributed with highest frequencies close to extreme values of the scale, as expected for freezing tolerance experiments that comprise susceptible damaged and tolerant non-damaged plants (Rizza et al. 2011). Thus, $F_{\mathrm{v}} / F_{\mathrm{m}}$ data for the 30 individual plants per accession were transformed to binomial scores using the scale mid-point $(0.38)$ or a more extreme value to identify especially the most tolerant accession (0.6) as threshold, values above the threshold being 1 (tolerant) and below the threshold being 0 (susceptible). These $1 / 0$ scores were subjected to logistic regression using the function $\mathrm{glm}$ of the R package stats (R Core Team 2014), including predictors for genotype and experiment effects. Resulting log of odds were transformed to obtain the estimated probability that each accession is tolerant to frost (hereafter called frost tolerance scores), which were used for GWAS. $F_{\mathrm{v}} / F_{\mathrm{m}}$ data from optimal and sub-optimal acclimation experiments were analysed both separately and together, thus estimating also an overall probability to tolerate different conditions.
Genome-wide association analyses were performed using and comparing alternative models, all fitted in GenStat (VSN International 2014). We could not use commonly available software, such as TASSEL (Bradbury et al. 2007) or EMMAX (Kang et al. 2010), because they require discrete genotypic data as input. However, the statistical approach we used is identical, namely testing the significance of marker effect in generalized linear models or linear mixed models, which correct for population structure or kinship or both. In a first step, a simple linear model was used that did not correct for population structure: $\mathrm{y}=$ marker + error, where $\mathrm{y}$ is the trait of interest, and marker is fixed. A second linear mixed model corrected for kinship between genotypes, using a variance component approach similar to the method implemented in EMMAX. The following model was used to test marker effects on each trait: $\mathrm{y}=$ marker + genotype + error, where genotype is a random effect and marker is fixed as before. The covariance between the different genotypes was structured by a kinship matrix, calculated as Euclidean distances based on marker scores. Different subset of equally spaced markers (160, 302 and 520 SNPs) were used for calculating the kinship matrix and their ability to correct for stratification was compared to a kinship matrix obtained using all the markers. A third fixed effects model corrected for population structure using the scores of the first $n$ principal components calculated using all markers: $\mathrm{y}=\sum_{i} \mathrm{PC}_{i}+$ marker + error, where marker and vectors of principal component scores were all fixed. Models including 10,15, 20 and 40 principal components were compared. This model uses the same approach of the method implemented in EIGENSTRAT (Price et al. 2006). A fourth linear mixed model corrected for population structure including principal components and markers as fixed factors and a kinship matrix as random, similar to the mixed linear model (MLM) included in the software package TASSEL. Resulting $p$ values from the association analyses were plotted versus the expected $p$ values, which are assumed to be uniformly distributed, under the null hypothesis.

A genome-wide significance threshold was calculated by the method described in $\mathrm{Li}$ and $\mathrm{Ji}$ (2005) for AVEQ08, AVEQ09 and for the whole dataset. Genome-wide $p$ values, indicating the strength of the genotype-phenotype association, were visualized as Manhattan plots using SNP map positions reported by Chaffin et al. (2016).

After the association analysis, intensity ratio frequency distributions of significantly associated markers were visually checked to exclude association due to a few outliers. This check has the same aim of filtering out markers with a low minor allele frequency (MAF) before association analysis, as is usual in standard approaches using discrete genotypes. 
Analysis of Linkage Disequilibrium (LD) decay as function of the pairwise distance between markers was conducted using the function LD.Measures from the $\mathrm{R}$ package $L D \operatorname{cor} S V$, correcting for population stratification using a covariance matrix between individuals (Desrousseaux et al. 2013). The pairwise marker correlations ( $R$ squared) within chromosomes were calculated and grouped in $1 \mathrm{cM}$ large bins. Then, the 90th percentiles of the $R$ squared distributions per bin were smoothed by a spline function.

\section{Results}

\section{Population structure}

In this study, hybridization intensities from the Illumina $6 \mathrm{~K}$ Oat SNP array were used to determine population structure in a collection of 131 European oat accessions (Fig. 1). Five diploid A. strigosa accessions were included in a first PCA and then removed from the following analyses, as they clearly clustered far from hexaploid oat samples (data not shown). Ward's hierarchical clustering revealed the presence of two main groups, which can be further subdivided giving a total of eight subgroups. In Fig. 2, the Ward's dendrogram is presented together with accession origin (country) and colour scales according to the phenotypic scores for lemma colour, frost tolerance, and days to heading. Analysis of principal components was first conducted on the whole population (Fig. 3) and then, as a nested analysis, on each of the two main groups (Online Resource 2). The pattern of clusterization obtained by PCA was in good accordance with Ward's clustering, supporting the dendrogram morphology (Fig. 3, Online Resource 2). Population structure analysis indicated a clustering related to geographical origin of the accessions, separating Mediterranean and Atlantic European accessions (group A) from Continental European accessions (group B) (Figs. 2, 3). Mediterranean and Atlantic European accessions are distinguished from Continental European accessions by PC1, while PC2 shows variability among Continental European accessions. Within the Continental European group, subgroup 2 contains accessions from Eastern countries (Hungary, Romania and Russia), subgroup 3 from Germany, subgroups 1 and 4 mainly from Central and Northern Europe (Austria, Czech Republic, Germany, Poland, and Sweden) (Figs. 2, 3). As for group A, subgroup 5 consists of three accessions from Bulgaria, subgroup 6 mainly from Great Britain and France, and subgroup 8 from Italy and Spain (Figs. 2, 3).

A two-level Analysis of Molecular Variance (AMOVA) found a significant difference between the Mediterranean/

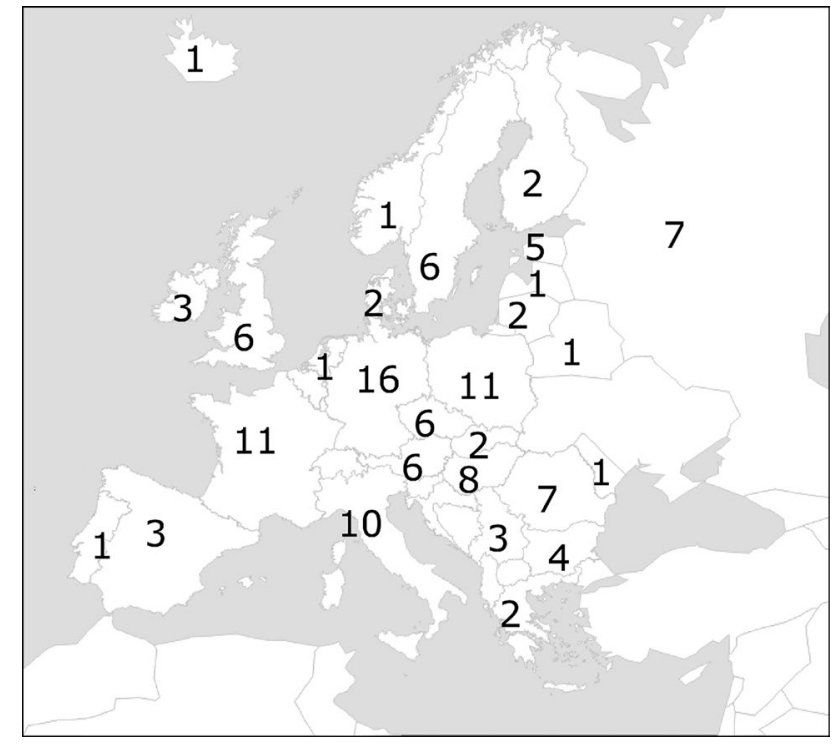

Fig. 1 Map of Europe showing the composition of the oat population in terms of country of origin. The number of accessions per origin country is indicated

Atlantic Europe (A) and the Continental Europe (B) groups, explaining $21.9 \%$ of the total variance (Table 1). Molecular variance within group A (152.8) was higher than within group B (81.2), in agreement with higher variability observed in group A for lemma colour, frost tolerance and heading date (Fig. 2). AMOVA also revealed significant differences among subgroups, accounting for $18.4 \%$ of the total variance, with the largest part of variance $(59.7 \%)$ remaining within subgroups.

\section{Phenotypic variation}

The phenotypic data for hullessness, lemma colour, days to heading and frost tolerance were scored in field trials or in growth chambers in 2008 and 2009. As only few accessions were present in both years, we decided to analyse the data for the accessions of the 2 years separately, hereafter called the AVEQ08 and AVEQ09 datasets.

Naked (or hulless) oats were represented by six accessions in AVEQ08 and three accessions in AVEQ09, two of them in common to both groups as standard cultivars. The accession adjusted values for hull percentage were clearly distributed into two classes, in the range 6-18\% for naked and multiflorous oats and 36-62\% for covered oats (Online Resource 3).

Lemma colour scores of the populations ranged from 1 to 5 , with a similar frequency distribution. The pigmented categories (grey, red and brown) together represented $20 \%$ of the total number of accessions (Online Resource 3). 
Fig. 2 Ward's dendrogram based on genotypic pairwise Euclidean distances. Labels indicate origin countries of the samples and colour gradients are relative to (a) mapping population composition ( grey for AVEQ08, black for AVEQ09, red for standard cultivars), (b) lemma colour accession means, $(c)$ frost tolerance scores (from blue for frost tolerant to red for frost susceptible) and (d) days to heading accession adjusted values (from blue for late-flowering accessions to red for early-flowering accessions). To visualize the phenotypic variation across the whole population, the year effects for frost tolerance scores and days to heading accession adjusted values were compensated using the eleven standard cultivars present in both populations

Days to heading was in the range 56-82 for AVEQ08 and 60-92 for AVEQ09 (Online Resource 3).

Chlorophyll fluorescence measurements were used to evaluate frost tolerance. The AVEQ08 and AVEQ09 accessions were separately phenotyped in five experiments per set. Frost tolerance scores ranged from 0.11 to 1 in AVEQ08 and from 0.07 to 0.98 in AVEQ09. Logistic regression provided a good description of the data for both populations and accession effects were highly significant $(p \leq 0.0001)$. Frequency distribution plots of frost tolerance scores can be found in Online Resource 3. Residual plots were performed and no substantial deviations were observed from the assumption of normally distributed residuals with constant variance.

\section{Correlation between structure and phenotypic variation}

Almost all accessions of group B had white or yellow lemmas, only $6 \%$ was red or black oat. The accessions in group A appeared to be more diverse with $26 \%$ red/brown oat, $17 \%$ grey oat and only $52 \%$ white/yellow oat (Fig. 2). Frost tolerance scores of the accessions correlated with population structure (Fig. 2). The most frosttolerant accessions belonged to the Mediterranean and Atlantic European group and, in particular, were grouped in three branches in subgroups 5, 6 and 7 (Fig. 2). In contrast, only a few moderately tolerant accessions were present in group B (gathered in subgroup 2), while subgroups 3 and 4 consisted entirely of accessions that were susceptible to frost. Heading date correlated with clustering as well (Fig. 2). The group B appeared quite homogeneous and was dominated by early-flowering or intermediate accessions, while group A showed large variation in flowering date, with some very early-flowering accessions in clusters 8 and 7 (especially from Italy) and late-flowering accessions in clusters 5, 6 and 7 , most of which were frost-tolerant.
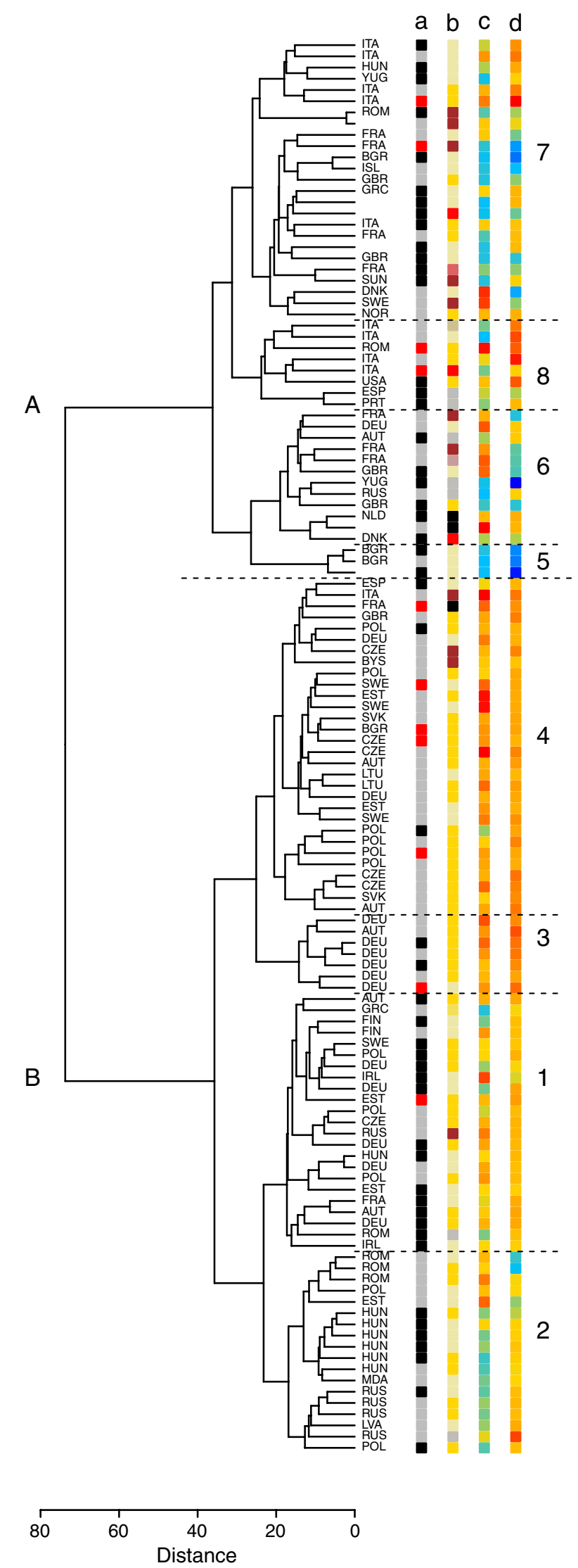


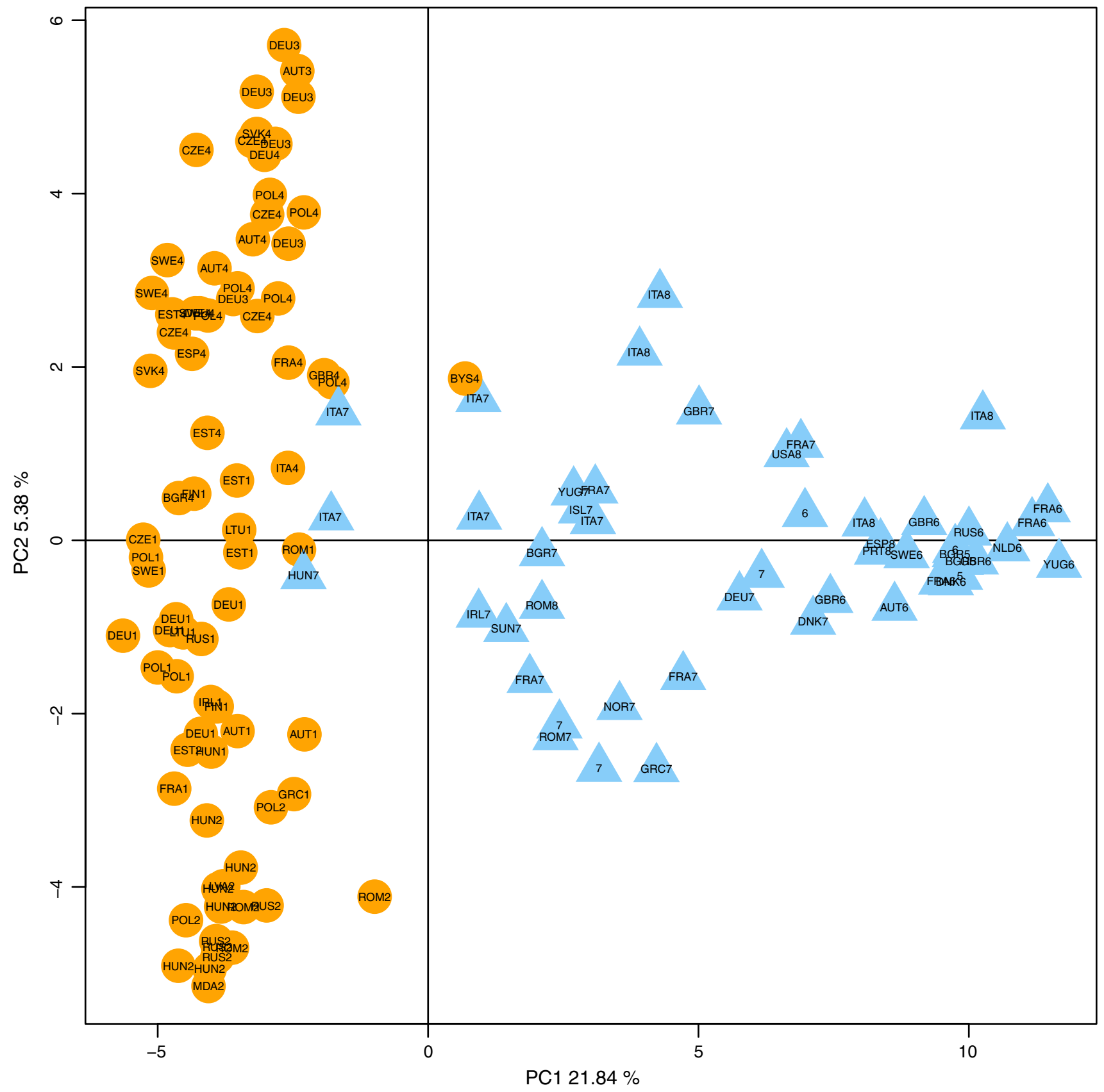

Fig. 3 Principal component analysis based on 3567 SNP hybridization intensity ratios. A scatter plot of PC1 (explaining $21.84 \%$ of the variance) versus PC2 (explaining $5.38 \%$ of the variance). Labels indicate origin countries of the samples and Ward cluster

Table 1 Two-level analysis of molecular variance (AMOVA), showing significant differences between the Mediterranean/Atlantic Europe (A) and the Continental Europe (B)

\begin{tabular}{lllll}
\hline Variance components & Variance & $\%$ Total & $p$ & $\Phi$-Statistics \\
\hline Between groups $\left(\sigma_{\mathrm{a}}^{2}\right)$ & 33.321 & 21.90 & $<0.0001$ & $\Phi_{\mathrm{CT}}=0.219$ \\
Among subgroups $\left(\sigma_{\mathrm{b}}^{2}\right)$ & 28.017 & 18.41 & $<0.0001$ & $\Phi_{\mathrm{SC}}=0.236$ \\
Within subgroups $\left(\sigma_{\mathrm{c}}^{2}\right)$ & 90.842 & 59.69 & & $\Phi_{\mathrm{ST}}=0.403$ \\
\hline
\end{tabular}

assignments. Colours and symbols according to the two main groups defined by Ward's clustering (group A, blue triangle; group B, orange circle)

\section{Correction for population stratification}

The GWAS results presented below were obtained using the model including a kinship matrix based on 302 uniformly spaced markers, since in most of the analyses it outperformed the other models in controlling false positives (Online Resource 7). The choice of this kinship matrix was also supported by the analysis of LD decay, indicating 


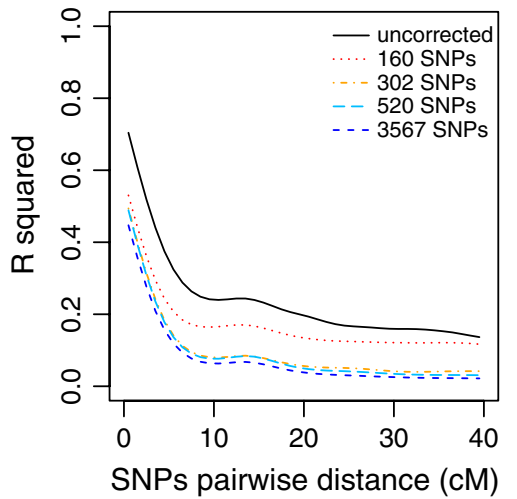

Fig. 4 Decay of linkage disequilibrium as function of the pairwise SNP distance

that the subset of 302 markers contains most of the genetic information; by adding more markers, only a slight improvement of LD correction is obtained (Fig. 4). The genome-wide significance thresholds (with $\alpha=0.05$ ) were $3.365,3.246$ and $3.551(-\log P)$ for AVEQ08, AVEQ09 and the whole dataset, respectively.

\section{Genome-wide association analyses for simple traits: hullessness and lemma colour}

Association analyses for lemma colour and hullessness were used for testing the effectiveness of our approach in detecting association for simple traits, whose phenotypic variation is probably explained by few major genes. Two strong associations were found for hull percentage in AVEQ08 in the linkage groups Mrg21 (five markers mapping from 123.7 to $130.8 \mathrm{cM}$ with the maximum $-\log P$ higher than 7) and Mrg04 (seven markers co-mapping at $45.6 \mathrm{cM}$ with $-\log P$ ranging from 7 to 9) (Fig. 5 and Online Resource 4). Other two markers were significantly associated to the trait in $\operatorname{Mrg} 09$ and $\operatorname{Mrg} 03(-\log P>5$ and $-\log P>4$, respectively). Moreover, four markers with unknown map position were significantly associated (Online Resource 4). Although phenotypic variation in AVEQ09 was low (only three naked oats) four regions were found significantly associated and three of them co-localized with the QTLs found in AVEQ08 on Mrg21, Mrg04 and Mrg09 (Online Resource 4). By mapping the naked condition (or multiflorous spikelet, which is genetically linked) as a qualitative trait across the whole population (AVEQ08 plus AVEQ09), the two QTLs in Mrg21 and Mrg04 were confirmed and two other markers were found significant in $\operatorname{Mrg} 21$ (at $178.3 \mathrm{cM}$ ) and $\mathrm{Mrg} 08$ (at $132.4 \mathrm{cM}$ ) (Fig. 5 and Online Resource 4).

GWAS for lemma color resulted in two robust associations with the markers GMI_ES15_c2369_181 in linkage group Mrg20 (14.7 cM) and GMI_ES_LB_8315 with unknown position, as they were significant for both mapping populations (Online Resource 5). Two other putative QTLs in linkage groups $\mathrm{Mrg} 03(56.2 \mathrm{cM})$ and $\mathrm{Mrg} 17$ $(84.3 \mathrm{cM})$ were detected in AVEQ08 and four QTLs in $\operatorname{Mrg02}(27.4), \operatorname{Mrg} 03(5.1 \mathrm{cM}), \operatorname{Mrg} 04(32.7 \mathrm{cM})$ and Mrg12 (35.3 cM) in AVEQ09 (Online Resource 5). Eleven significant markers for AVEQ09 were excluded because of the presence of outliers.

\section{Genome-wide association analyses for complex traits: frost tolerance and heading date}

Association analysis for frost tolerance detected six significant markers, three for AVEQ08 in Mrg01 (101.5 cM) and Mrg11 (8.8-9.8 cM) and three for AVEQ09 in Mrg12 $(58.5 \mathrm{cM}), \operatorname{Mrg} 20(156.7 \mathrm{cM})$ and $\operatorname{Mrg} 21(205.7 \mathrm{cM})$ (Table 2). The $-\log P$ values for marker effects for AVEQ08 are shown in Fig. 6 as a Manhattan plot. Four significant markers detected for AVEQ08 (in Mrg04, Mrg12 and two unknown positions) were excluded because of the presence of outliers (Fig. 6). The marker GMI_ES05_c13603_259 mapping in $\operatorname{Mrg} 11(9.8 \mathrm{cM})$ showed the most significant effect, with $-\log P$ greater than six. Association mapping results were not very sensitive to the threshold used for the
Fig. 5 Manhattan plot of $-\log P$ values calculated by GWAS for hull percentage in AVEQ08 (a) and for the qualitative naked status in the whole collection (b). The linkage group Mrg21 is shown with marker genetic position relative to the most recent consensus map (Chaffin et al. 2016). The horizontal dotted line represents the genome-wide significance threshold
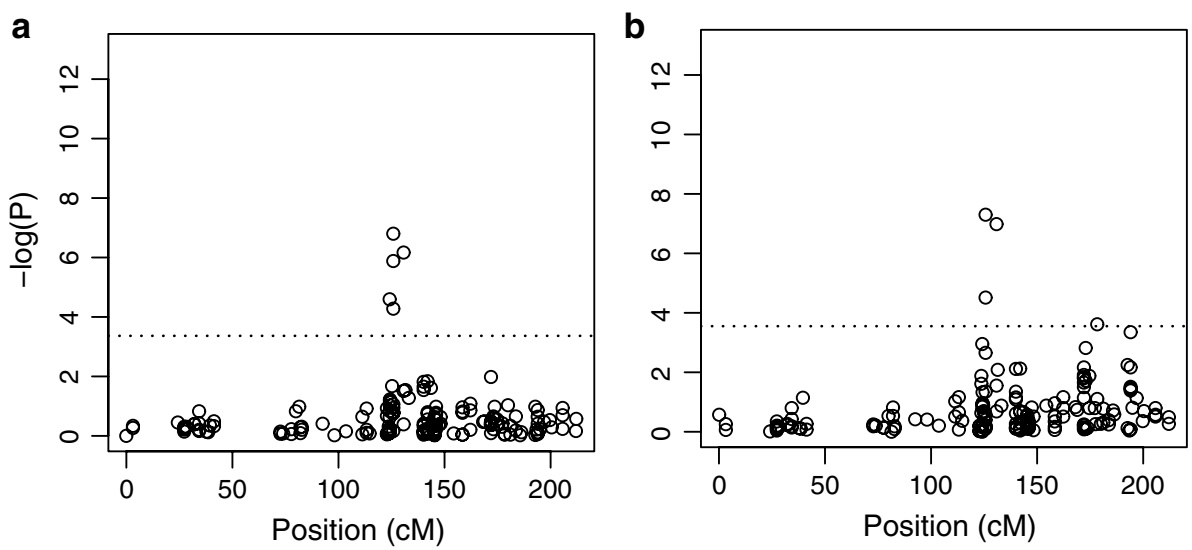
Table 2 List of associated markers for frost tolerance in AVEQ08 and AVEQ09

\begin{tabular}{|c|c|c|c|c|}
\hline Locus_Name & $-\log P$ & Group & Position & Chrom \\
\hline \multicolumn{5}{|l|}{ AVEQ08 overall } \\
\hline GMI_ES01_c1416_473 & 3.72 & $\operatorname{Mrg01}$ & 101.5 & $5 \mathrm{C}$ \\
\hline GMI_ES01_c30278_396 & 3.38 & $\operatorname{Mrg} 11$ & 8.8 & $1 \mathrm{C}$ \\
\hline GMI_ES05_c13603_259 & 5.77 & $\operatorname{Mrg} 11$ & 9.8 & $1 \mathrm{C}$ \\
\hline \multicolumn{5}{|l|}{ AVEQ09 overall } \\
\hline GMI_DS_LB_1269 & 3.27 & $\operatorname{Mrg} 12$ & 58.5 & $13 \mathrm{~A}$ \\
\hline GMI_ES01_c26788_88 & 3.39 & $\operatorname{Mrg} 20$ & 156.7 & $19 \mathrm{~A}$ \\
\hline GMI_GBS_67251 & 3.59 & $\operatorname{Mrg} 21$ & 205.7 & $8 \mathrm{~A}$ \\
\hline \multicolumn{5}{|l|}{ AVEQ08 sub-opt } \\
\hline GMI_DS_CC7686_215 & 3.45 & Mrg03 & 58.6 & $4 \mathrm{C}$ \\
\hline GMI_ES02_c911_580 & 3.50 & $\operatorname{Mrg} 15$ & 87.2 & $2 \mathrm{C}$ \\
\hline GMI_ES01_c10257_104 & 4.10 & $\operatorname{Mrg} 23$ & 28.5 & $11 \mathrm{~A}$ \\
\hline GMI_ES15_c6451_437 & 3.84 & $\operatorname{Mrg} 23$ & 28.5 & $11 \mathrm{~A}$ \\
\hline GMI_GBS_17527 & 3.70 & $\operatorname{Mrg} 33$ & 26.3 & $15 \mathrm{~A}$ \\
\hline \multicolumn{5}{|l|}{ AVEQ08 optimal } \\
\hline GMI_DS_CC6027_225 & 4.28 & Mrg02 & 27.4 & $9 \mathrm{D}$ \\
\hline GMI_ES15_c276_702 & 3.56 & $\operatorname{Mrg} 11$ & 3.7 & $1 \mathrm{C}$ \\
\hline GMI_ES05_c13603_259 & 4.25 & $\operatorname{Mrg} 11$ & 9.8 & $1 \mathrm{C}$ \\
\hline GMI_ES_CC16445_119 & 3.54 & $\operatorname{Mrg} 17$ & 114.5 & $3 \mathrm{C}$ \\
\hline GMI_ES_CC11076_204 & 3.66 & Mrg20 & 97.1 & $19 \mathrm{~A}$ \\
\hline \multicolumn{5}{|l|}{ AVEQ09 optimal } \\
\hline GMI_ES02_c3577_672 & 3.87 & Mrg01 & 117.4 & $5 \mathrm{C}$ \\
\hline GMI_DS_LB_7011 & 3.49 & Mrg08 & 142 & $12 \mathrm{D}$ \\
\hline GMI_GBS_67251 & 3.76 & $\operatorname{Mrg} 21$ & 205.7 & $8 \mathrm{~A}$ \\
\hline GMI_DS_LB_6024 & 3.51 & $\operatorname{Mrg} 28$ & 54.2 & $17 \mathrm{~A}$ \\
\hline GMI_ES02_c27548_253 & 3.86 & NA & NA & NA \\
\hline
\end{tabular}

binomial transformation of $F_{\mathrm{v}} / F_{\mathrm{m}}$ values (data not shown). If separately analysed, frost tolerance scores from the two hardening conditions (optimal and sub-optimal hardening) were associated to different regions (Table 2). No markers were detected for frost tolerance scores measured after suboptimal hardening for AVEQ09.

Regarding days to heading, in total seven markers were significant, but one of them with unknown map position was excluded due to the presence of outliers. Significant associations were found in $\operatorname{Mrg} 01(117.9 \mathrm{cM}), \operatorname{Mrg} 02$ $(33 \mathrm{cM})$ and $\operatorname{Mrg} 13(58.6 \mathrm{cM})$ for AVEQ08 and in Mrg20 (18 and $115.6 \mathrm{cM})$ and $\mathrm{Mrg} 21(122.8 \mathrm{cM})$ for AVEQ09 (Online Resource 6).

\section{Discussion}

\section{SNP signals analysis}

In oat genetic diversity studies, dominant and co-dominant markers such as AFLP, SSR and DArT have been used to analyse DNA samples extracted from bulks of several individuals, to take into account the within-accession genetic variability ( $\mathrm{Fu}$ et al. 2005; Achleitner et al. 2008; Tinker et al. 2009; Montilla-Bascon et al. 2013). Especially when within-accession variability is expected to be large, as in the case of landraces, bulking more plants allows sampling genetic variability while limiting genotyping costs.

In the present work, DNA samples from bulks of 10 plants were analysed using an Infinium SNP array. We genotyped a collection of European oat accessions obtained from genebanks, including modern and old varieties as well as a few landraces, for which a certain degree of genetic heterogeneity was expected. Due to a high signal to noise ratio, SNP arrays enable accurate estimation of allelic ratios in polyploids (e.g., Bertioli et al. 2014, using a GoldenGate array in tetraploid peanut; Bourke et al. 2015, using an Infinium array in tetraploid potato; Bassil et al. 2015, using an Axiom array in octaploid strawberry). To what extent they are able to detect low frequency alleles in bulks of samples has not been quantified. We used SNP hybridization intensity ratios as continuous variables representing accession-level (bulk) allele frequencies. Similar to genotypes for individuals, bulk allele frequencies can be statistically associated to phenotypes measured in bulks in GWAS. For instance, Montilla-Bascon et al. (2015) performed a GWAS for crown rust and powdery mildew using SNP data of bulks of oat varieties and landraces. Bulking enabled us to reduce genotyping costs. Moreover, using intensity ratios, SNP signals were not interpreted as discrete genotype classes, reducing the risk of loss useful information for genetic diversity analysis and GWAS (Miller et al. 2013; Myles et al. 2015). This appears particularly relevant for allopolyploid species, as SNP probes may or may not be subgenome-specific (Bassil et al. 2015), making genotype calling a challenging, time-consuming and error-prone task.

In association studies, the presence of population structure can be a source of false positives and a statistical correction is usually included in the GWAS model. We used several models which correct for population stratification in different ways: (1) including principal components as fixed cofactors, similar to the approach implemented in EIGENSTRAT (Price et al. 2006); (2) using a mixed model including a kinship matrix, as also implemented in e.g., TASSEL (Bradbury et al. 2007) or EMMAX (Kang et al. 2010); (3) including in a mixed model principal components as fixed factors and a kinship matrix as a random factor, implemented in TASSEL as well. Unfortunately, it was not possible to use standard software packages commonly used for GWAS because they require discrete genotypes as input. While the approach we used can be considered equivalent to those most commonly used, the calculation of the kinship matrix was slightly different. We point out that, 

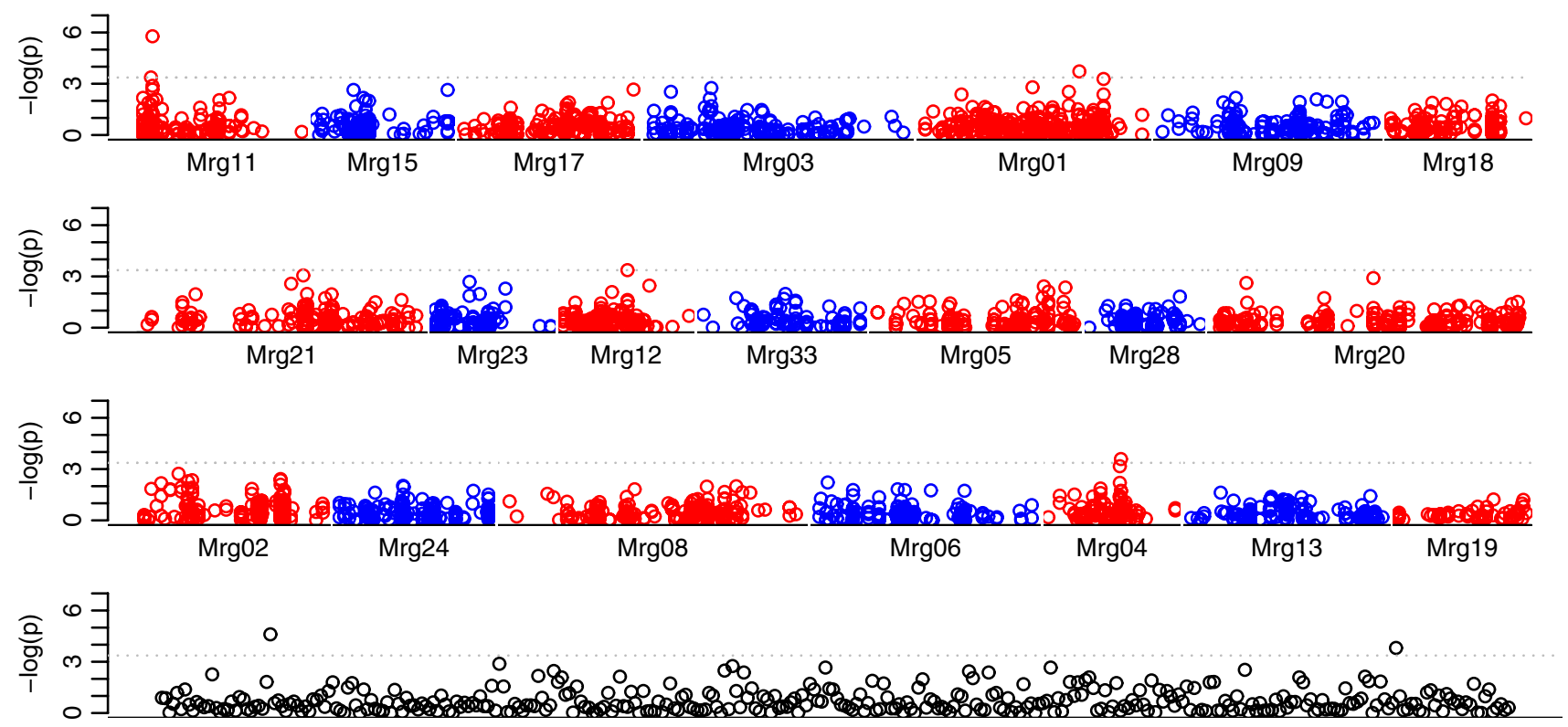

Fig. 6 Manhattan plots of $-\log P$ values calculated by GWAS for frost tolerance in AVEQ08. Genetic position of markers is relative to the most recently available consensus map by Chaffin et al. (2016).
Black points indicate unmapped markers. The horizontal dotted line represents the genome-wide significance threshold

temperatures. In particular, they mainly clustered into two branches of the Ward's dendrogram in subgroups 6 and 7, and the available pedigrees lead to the ancestors Winter Turf (also called Grey winter) and Grise d'hiver, two European winter landraces with many similar features (Stanton 1955; Hunter and Carson 1949). The SNP array we used has been shown to correctly predict the growth habit in a diverse collection of 595 accessions from USA, Canada, Brazil and Europe (Tinker et al. 2014), but in contrast to that study we did not obtain a single cluster of winter types (or frost-tolerant types). This could have several possible explanations: (1) the winter types analysed by Tinker et al. (2014) were mainly from USA and this may have underestimated the diversity of worldwide winter types; (2) admixture may have taken place in the European material, so that the modern varieties included in our study do not strictly reflect any more a stratification related to growth habit.

The taxonomical distinction that used to be made between Avena sativa L. (common oat) and Avena sativa spp. byzantina $\mathrm{K}$. Koch (red oat) is another source of stratification detected by many genetic diversity studies including hexaploid oat (Fu et al. 2005; Achleitner et al. 2008; Montilla-Bascon et al. 2013; Newell et al. 2011), which may suggest the existence of two significantly differentiated gene pools. Based on the mode of floret separation (Diederichsen 2007), the only red oat included in our population is the Italian variety named Argentina (subgroup 8). Consistent with previous studies on the distance between common and red oat, the variety Argentina was genetically 
the most distinct accession. In the PCA of group A, Argentina had an extreme position (data not shown). Subgroup 8 was highly diverse, as indicated by the highest withingroup Mean Sum of Squares (178).

\section{Genome-wide association analyses for simple traits}

We performed GWAS using hybridization ratios from 3567 SNP markers. This surpassed the minimum number of 2000 markers (one marker every $\mathrm{cM}$ ) proposed for genome-wide association studies in oat, based on the analysis of LD in a large set of 1205 oat lines (Newell et al. 2011). Although the number of markers we used suggests a good genome coverage, we cannot exclude the presence of gaps, since for about 1000 markers the genetic map position is currently unknown. A higher number of markers would increase the average level of linkage between markers and QTLs and therefore the power of QTL detection.

According to the currently accepted genetic model for hullessness, the incompletely dominant $N 1$ gene expression is modulated by genetic background (Ougham et al. 1996). The N1 locus was previously identified in linkage group TM-5 (Terra x Marion) (De Koeyer et al. 2004) which is homologous to linkage group Mrg21. Using hull percentage, we found two robust associations in linkage groups $\mathrm{Mrg} 21$ and $\mathrm{Mrg} 04$ (around 125 and at $45.6 \mathrm{cM}$, respectively; Fig. 5 and Online Resource 4) and this finding was consistent across the two mapping populations. By mapping the naked status (strictly linked to multiflorous spikelet) as a qualitative trait, an additional significant association was found in Mrg21 at $178.3 \mathrm{cM}$ (Fig. 5), mapping closer to the marker cdo482 $(199.2 \mathrm{cM})$ reported by De Koeyer et al. (2004) as associated to locus N1 in the bi-parental population Terra x Marion. De Koeyer et al. (2004) also found an additional association using a quantitative score for hullessness (hull percentage), but unfortunately that marker was not linked to any linkage group.

The association we found for lemma colour with the marker GMI_ES15_c2369_181 in linkage group Mrg20 $(14.7 \mathrm{cM})$ has never been identified earlier. However, this association showed a very significant $p$ value $(-\log P>5$ in AVEQ08 and $-\log P>7$ in AVEQ09) and most importantly was consistent across the two mapping populations, supporting our finding. These results showed that our GWAS approach based on SNP array intensity ratios was effective to detect significant associations for simply inherited traits.

\section{Genome-wide association analyses for frost tolerance and heading date}

Significant associations for frost tolerance were found in linkage groups $\operatorname{Mrg} 01(101.5 \mathrm{cM})$ and $\operatorname{Mrg} 11(9.8 \mathrm{cM})$ for population AVEQ08 and in linkage groups Mrg12
(58.5), Mrg20 (156.7 cM) and Mrg21 (205.7) for AVEQ09 (Table 2).

Previous studies have identified several QTLs related to frost tolerance or winter hardiness. Nava et al. (2012) cloned the homologous genes for Vrn-l and Ft-1 (Vrn3). Vrn1-T4 showed the highest homology to the wheat gene Vrn-Al. In the Kanota $\mathrm{x}$ Ogle map (KO; facultative $\mathrm{x}$ spring type) (Wight et al. 2003), Vrn1-T4 co-located with a known QTLs affecting flowering time and crown freezing tolerance on linkage group 24_26_34 (Nava et al. 2012; Tinker et al. 2009; Holland et al. 2002; Wooten et al. 2008). This QTL including the Vrn-1 locus is located in a region of about $10 \mathrm{cM}$ from 130 to $140 \mathrm{cM}$ in $\mathrm{Mrg} 20$ of the consensus map, which is very close to the main association we detected in Mrg20 at $143.6 \mathrm{cM}$ for AVEQ09. However, sequence alignment and map homology indicated that a second copy of Vrn-1 may be located on the homoeologous KO group 22_44_18 (Nava et al. 2012), corresponding to Mrg21. These two loci could represent the associations we found for AVEQ09 in Mrg20 (156.7 cM), which maps $15 \mathrm{cM}$ apart from $V r n-1$, and $\mathrm{Mrg} 21$ (at $205.7 \mathrm{cM}$ ).

The locus Fr-2, affecting frost tolerance in Triticeae, has not been identified yet in oat. Although one of the QTLs we found could potentially represent $F r$-2, currently we do not have enough data to discuss it. According to the $6 \mathrm{~K} \mathrm{SNP}$ array annotation (Tinker et al. 2014), the significant marker we found in $\mathrm{Mrg} 01(101.5 \mathrm{cM})$ for AVEQ08 is located in the reciprocal genomic translocation 17A-7C. This region has been previously associated to winter survival and crown freezing tolerance tracking this translocation by FISH in the population Wintok x Fulghum (Santos et al. 2006) and using marker-based QTL mapping in the population Fulghum x Norline (Maloney et al. 2011), although its effect on frost tolerance was not confirmed in the KO population (Wooten et al. 2008). Unfortunately, due to the low resolution of the Fulghum $x$ Norline map it is not possible to make a precise comparison of the QTL position.

Using the KO population Wooten et al. (2008) identified seven QTLs for crown freezing tolerance, among which the QTL with the largest effect mapped on KO 24_26_34, most probably detecting the Vrn-l locus (Mrg20) described above. Six other QTLs with minor effects were located in KO linkage groups $21+46 \_31+4,16 \_23,25,3+38$, $11 \_41+20$ and 22_44_18. The QTL found in KO $21+46 \_31+4$, and in particular marker BCD1230B, maps in $\operatorname{Mrg} 11$ at $40.8 \mathrm{cM}$ in the new consensus map. The most robust association we found in $\operatorname{Mrg} 11$ maps at $9.8 \mathrm{cM}$, which therefore could be considered a new QTL.

The two hardening condition had an effect on association mapping as different QTLs were detected, suggesting that the accessions interact differently with the different hardening conditions. Significant associations for frost tolerance in $\operatorname{Mrg} 23(28.5 \mathrm{cM})$ and $\operatorname{Mrg} 33(26.3 \mathrm{cM})$ were 
detected only for sub-optimal acclimation condition experiments (Table 2) and were not found in earlier studies. The main QTLs in $\operatorname{Mrg} 11, \operatorname{Mrg} 01, \operatorname{Mrg} 20$ and $\operatorname{Mrg} 21$ were detected both using the optimal hardening condition and using the overall frost tolerance scores (Table 2).

The differences in QTLs found between the two datasets analysed here may partly be related to the difference in genetic structure (Fig. 2a). AVEQ08 was well-balanced, representing all the genetic subgroups identified by Ward's clustering and PCA. AVEQ09 was narrower in terms of subgroups and also had a smaller size, so a lower statistical power may be expected.

Author contribution statement VT and CUG conceived the study. VT planned and supervised the genotyping work. CUG coordinated the AVEQ project in which FR and FWB carried out the growth chamber experiments for frost tolerance evaluation. CM and RG developed the mapping populations, extracted the DNA samples and contributed to the frost tolerance evaluation. GT performed the statistical analyses of phenotypic data, genetic diversity, and genome-wide association and prepared the manuscript. REV contributed to SNP data curation and association analysis. MJP provided statistical support for genome-wide association analyses. REV and MJMS supervised all the data analyses and contributed to the interpretation of the data. REV, MJMS, MJP, FR, FWB and VT commented and revised the manuscript.

Note added in proof Klos et al. (2016) detected a similar population structure in a North American oat collection. The QTL for heading date on Mrg02 was confirmed by this study.

\begin{abstract}
Acknowledgments The authors wish to thank Fabio Reggiani, Donata Pagani and Nadia Faccini for their technical assistance in plant phenotyping, and Nicholas Tinker and Jessica Schlueter for advice on and access to preliminary versions of the consensus map prior to publication. This research was carried out partly within the project 'Avena Genetic Resources for Quality in Human Consumption (AVEQ)', funded by the European Commission (AGRI GEN RES action 061), and FAO-RGV (Italian Ministry of Agriculture funded) projects. REV and MJMS were partially supported by the TKI Polyploids project (H263). The funders had no role in study design, data collection and analysis, decision to publish, or preparation of the manuscript.
\end{abstract}

\section{Compliance with ethical standards}

Conflict of interest The authors declare that they have no conflict of interest.

Open Access This article is distributed under the terms of the Creative Commons Attribution 4.0 International License (http://creativecommons.org/licenses/by/4.0/), which permits unrestricted use, distribution, and reproduction in any medium, provided you give appropriate credit to the original author(s) and the source, provide a link to the Creative Commons license, and indicate if changes were made.

\section{References}

Achleitner A, Tinker NA, Zechner E, Buerstmayr H (2008) Genetic diversity among oat varieties of worldwide origin and associations of AFLP markers with quantitative traits. Theor Appl Genet 117:1041-1053

Bassil NV et al (2015) Development and preliminary evaluation of a $90 \mathrm{~K}$ Axiom ${ }^{\circledR}$ SNP array for the allo-octoploid cultivated strawberry Fragaria $\times$ ananassa. BMC Genom 16:155. doi:10.1186/ s12864-015-1310-1

Bertioli DJ, Ozias-Akins P, Chu Y, Dantas KM, Santos SP, Gouvea E, Guimaraes PM, Leal-Bertioli SC, Knapp SJ, Moretzsohn MC (2014) The use of SNP markers for linkage mapping in diploid and tetraploid peanuts. G3(4):89-96

Bourke PM, Voorrips RE, Visser RGF, Maliepaard C (2015) The double reduction landscape in tetraploid potato as revealed by a high-density linkage map. Genetics 201:853-863. doi:10.1534/ genetics.115.181008

Bradbury PJ, Zhang Z, Kroon DE, Casstevens TM, Ramdoss Y, Buckler ES (2007) TASSEL: software for association mapping of complex traits in diverse samples. Bioinformatics 23:2633-2635

Casao MC, Igartua E, Karsai I, Lasa JM, Gracia MP, Casas AM (2011) Expression analysis of vernalization and day-length response genes in barley (Hordeum vulgare L.) indicates that VRNH2 is a repressor of PPDH2 (HvFT3) under long days. J Exp Bot 62:1939-1949

Chaffin AS, Huang YF, Smith S, Bekele WA, Babiker E, Gnanesh BN, Foresman BJ, Blanchard SG, Jay JJ, Reid RW, Wight CP, Chao S, Oliver R, Islamovic E, Kolb FL, McCartney C, Mitchell Fetch JW, Beattie AD, Bjørnstad Å, Bonman JM, Langdon T, Howarth CJ, Brouwer CR, Jellen EN, Klos KE, Poland JA, Hseih TF, Brown R, Jackson E, Schlueter JA, Tinker NA (2016) A consensus map in cultivated hexaploid oat reveals conserved grass synteny with substantial sub-genome rearrangement. Plant Genome 9. doi:10.3835/plantgenome2015.10.0102

Chen A, Dubcovsky J (2012) Wheat TILLING mutants show that the vernalization gene VRN1 down-regulates the flowering repressor VRN2 in leaves but is not essential for flowering. PLoS Genet 8:e1003134

De Koeyer DL, Tinker NA, Wight CP, Deyl J, Burrows VD, O'Donoughue LS, Lybaert A, Molnar SJ, Armstrong KC, Fedak G, Wesenberg DM, Rossnagel BG, McElroy AR (2004) A molecular linkage map with associated QTLs from a hulless x covered spring oat population. Theor Appl Genet 108(7):1285-1298

Desrousseaux D, Sandron F, Siberchicot A, Cierco-Ayrolles C and Mangin B (2013) LDcorSV: Linkage disequilibrium corrected by the structure and the relatedness. $\mathrm{R}$ package version 1.3.1. http://CRAN.R-project.org/package=LDcorSV. Accessed 13 Jan 2016

Dhillon T, Pearce SP, Stockinger EJ, Distelfeld A, Li C, Knox AK, Vashegyi I, Vagujfalvi A, Galiba G, Dubcovsky J (2010) Regulation of freezing tolerance and flowering in temperate cereals: the VRN-1 connection. Plant Physiol 153:1846-1858

Diederichsen A (2007) Assessments of genetic diversity within a world collection of cultivated hexaploid oat (Avena sativa L.) based on qualitative morphological characters. Genet Resour Crop Evol 55:419-440

Excoffier L, Smouse PE, Quattro JM (1992) Analysis of molecular variance inferred from metric distances among DNA haplotypes: application to human mitochondrial DNA restriction data. Genetics 131:479-491 
FAOSTAT (2015). http://faostat3.fao.org/home/E. Accessed 11 Nov 2015

Fisk SP, Cuesta-Marcos A, Cistue L, Russell J, Smith KP, Baenziger S, Bedo Z, Corey A, Filichkin T, Karsai I, Waugh R, Hayes PM (2013) FR-H3: a new QTL to assist in the development of fallsown barley with superior low temperature tolerance. Theor Appl Genet 126:335-347

Francia E, Rizza F, Cattivelli L, Stanca AM, Galiba G, Toth B, Hayes PM, Skinner JS, Pecchioni N (2004) Two loci on chromosome $5 \mathrm{H}$ determine low-temperature tolerance in a 'Nure' (winter) $\mathrm{x}$ 'Tremois' (spring) barley map. Theor Appl Genet 108:670-680

Francia E, Barabaschi D, Tondelli A, Laido G, Rizza F, Stanca AM, Busconi M, Fogher C, Stockinger EJ, Pecchioni N (2007) Fine mapping of a HvCBF gene cluster at the frost resistance locus Fr-H2 in barley. Theor Appl Genet 115:1083-1091

Fricano A, Rizza F, Faccioli P, Pagani D, Pavan P, Stella A, Rossini L, Piffanelli P, Cattivelli L (2009) Genetic variants of HvCbf14 are statistically associated with frost tolerance in a European germplasm collection of Hordeum vulgare. Theor Appl Genet 119:1335-1348

Fu YB, Peterson GW, Williams D, Richards KW, Fetch JM (2005) Patterns of AFLP variation in a core subset of cultivated hexaploid oat germplasm. Theor Appl Genet 111:530-539

Galiba G, Quarrie SA, Sutka J, Morgounov A, Snape JW (1995) RFLP mapping of the vernalization (Vrn1) and frost resistance (Fr1) genes on chromosome 5A of wheat. Theor Appl Genet 90:1174-1179

Hemming MN, Peacock WJ, Dennis ES, Trevaskis B (2008) Lowtemperature and daylength cues are integrated to regulate FLOWERING LOCUS T in barley. Plant Physiol 147:355-366

Holland JB, Portyanko VA, Hoffman DL, Lee M (2002) Genomic regions controlling vernalization and photoperiod responses in oat. Theor Appl Genet 105:113-126

Huang YF, Poland JA, Wight CP, Jackson EW, Tinker NA (2014) Using genotyping-by-sequencing (GBS) for genomic discovery in cultivated oat. PLoS ONE 9:e102448

Hunter H, Carson GP (1949) The breeding history of Picton oats and observations on the behaviour of certain oat crosses. J Agric Sci 39:119-124

Kang HM, Sul JH, Service SK, Zaitlen NA, Kong SY, Freimer NB, Sabatti C, Eskin E (2010) Variance component model to account for sample structure in genome-wide association studies. Nat Genet 42:348-354

Klos KE, Huang YF, Bekele WA, Obert DE, Babiker E, Beattie AD, Bjørnstad Å, Bonman JM, Carson ML, Chao S, Gnanesh BN et al. (2016) Population genomics related to adaptation in elite oat germplasm. Plant Genome 0. doi:10.3835/plantgenome2015.10.0103

Knox AK, Dhillon T, Cheng H, Tondelli A, Pecchioni N, Stockinger EJ (2010) CBF gene copy number variation at Frost Resistance-2 is associated with levels of freezing tolerance in temperate-climate cereals. Theor Appl Genet 121:21-35

Li J, Ji L (2005) Adjusting multiple testing in multilocus analyses using the eigenvalues of a correlation matrix. Heredity 95:221-227

Limin AE, Fowler DB (2006) Low-temperature tolerance and genetic potential in wheat (Triticum aestivum L.): response to photoperiod, vernalization, and plant development. Planta 224:360-366

Lipman E, Maggioni L, Knüpffer H, Ellis R, Leggett JM, Kleijer G, Faberová I, Le Blanc A, compilers (2005) Cereal Genetic Resources in Europe. Report of a Cereals Network, First Meeting, 3-5 July 2003, Yerevan, Armenia/Report of a Working Group on Wheat, Second Meeting, 22-24 September 2005, La Rochelle, France. International Plant Genetic Resources Institute, Rome, Italy

Maloney PV, Lyerly JH, Wooten DR, Anderson JM, Livingston DP, Brown-Guedira G, Marshall D, Murphy JP (2011) Marker development and quantitative trait loci in a fall-sown Oat recombinant inbred population. Crop Sci 51:490

Miller AJ, Matasci N, Schwaninger H, Aradhya MK, Prins B, Zhong GY, Simon C, Buckler ES, Myles S (2013) Vitis phylogenomics: hybridization intensities from a SNP array outperform genotype calls. PLoS One 8:e78680

Montilla-Bascon G, Rispail N, Sanchez-Martin J, Rubiales D, Mur LA, Langdon T, Howarth CJ, Prats E (2015) Genome-wide association study for crown rust (Puccinia coronata $\mathrm{f}$. sp. avenae) and powdery mildew (Blumeria graminis f. sp. avenae) resistance in an oat (Avena sativa) collection of commercial varieties and landraces. Front Plant Sci 6:103

Montilla-Bascón G, Sánchez-Martín J, Rispail N, Rubiales D, Mur L, Langdon T, Griffiths I, Howarth C, Prats E (2013) Genetic diversity and population structure among oat cultivars and landraces. Plant Mol Biol Rep 31:1305-1314

Myles S, Mahanil S, Harriman J, Gardner KM, Franklin JL, Reisch BI, Ramming DW, Owens CL, Li L, Buckler ES, Cadle-Davidson L (2015) Genetic mapping in grapevine using SNP microarray intensity values. Mol Breed 35:88

Nava IC, Wight CP, Pacheco MT, Federizzi LC, Tinker NA (2012) Tagging and mapping candidate loci for vernalization and flower initiation in hexaploid oat. Mol Breed 30:1295-1312

Newell MA, Cook D, Tinker NA, Jannink JL (2011) Population structure and linkage disequilibrium in oat (Avena sativa $\mathrm{L}$.): implications for genome-wide association studies. Theor Appl Genet 122:623-632

Oliver RE, Tinker NA, Lazo GR, Chao S, Jellen EN, Carson ML, Rines HW, Obert DE, Lutz JD, Shackelford I, Korol AB, Wight CP, Gardner KM, Hattori J, Beattie AD, Bjornstad A, Bonman JM, Jannink JL, Sorrells ME, Brown-Guedira GL, Mitchell Fetch JW, Harrison SA, Howarth CJ, Ibrahim A, Kolb FL, McMullen MS, Murphy JP, Ohm HW, Rossnagel BG, Yan W, Miclaus KJ, Hiller J, Maughan PJ, Redman Hulse RR, Anderson JM, Islamovic E, Jackson EW (2013) SNP discovery and chromosome anchoring provide the first physically-anchored hexaploid oat map and reveal synteny with model species. PLoS One 8:e58068

Ougham HJ, Latipova G, Valentine J (1996) Morphological and biochemical characterization of spikelet development in naked oats (Avena sativa). New Phytol 134:5-12

Paradis E (2010) pegas: an R package for population genetics with an integrated-modular approach. Bioinformatics 26:419-420

Park S, Lee C-M, Doherty CJ, Gilmour SJ, Kim Y-S, Thomashow MF (2015) Regulation of the Arabidopsis CBF regulon by a complex low-temperature regulatory network. Plant J 82:193-207

Price AL, Patterson NJ, Plenge RM, Weinblatt ME, Shadick NA, Reich D (2006) Principal components analysis corrects for stratification in genome-wide association studies. Nat Genet 38:904-909

Rizza F, Crosatti C, Stanca AM, Cattivelli L (1994) Studies for assessing the influence of hardening on cold tolerance of barley genotypes. Euphytica 75:131-138

Rizza F, Pagani D, Stanca AM, Cattivelli L (2001) Use of chlorophyll fluorescence to evaluate the cold acclimation and freezing tolerance of winter and spring oats. Plant Breed 120:389-396

Rizza F, Pagani D, Gut M, Prášil IT, Lago C, Tondelli A, Orrù L, Mazzucotelli E, Francia E, Badeck FW, Crosatti C, Terzi V, Cattivelli L, Stanca AM (2011) Diversity in the response to low temperature in representative barley genotypes cultivated in Europe. Crop Sci 51:2759

Santos AG, Livingston DP, Jellen EN, Wooten DR, Murphy JP (2006) A cytological marker associated with winterhardiness in oat. Crop Sci 46:203

Stanca AM, Romagosa I, Takeda K, Lundborg T, Terzi V, Cattivelli L (2003) Diversity in abiotic stresses tolerances. In: von Bothmer 
R, van Hintum T, Knupffer H, Sato K (eds) Diversity in barley (Hordeum vulgare). Elsevier Science, Amsterdam, pp 179-199

Stanton TR (1955) Oat identification and classification. US Dept. of Agriculture, Washington

Szucs P, Skinner JS, Karsai I, Cuesta-Marcos A, Haggard KG, Corey AE, Chen TH, Hayes PM (2007) Validation of the VRN-H2/ VRN-H1 epistatic model in barley reveals that intron length variation in VRN-H1 may account for a continuum of vernalization sensitivity. Mol Genet Genom 277:249-261

R Core Team (2014) R: a language and environment for statistical computing. R Foundation for Statistical Computing, Vienna, Austria. ISBN 3-900051-07-0. http://www.R-project.org/

Tinker NA, Kilian A, Wight CP, Heller-Uszynska K, Wenzl P, Rines HW, Bjornstad A, Howarth CJ, Jannink JL, Anderson JM, Rossnagel BG, Stuthman DD, Sorrells ME, Jackson EW, Tuvesson S, Kolb FL, Olsson O, Federizzi LC, Carson ML, Ohm HW, Molnar SJ, Scoles GJ, Eckstein PE, Bonman JM, Ceplitis A, Langdon T (2009) New DArT markers for oat provide enhanced map coverage and global germplasm characterization. BMC Genom 10:39

Tinker NA, Chao S, Lazo GR, Oliver RE, Huang Y-F, Poland JA, Jellen EN, Maughan PJ, Kilian A, Jackson EW (2014) A SNP genotyping array for hexaploid oat. Plant Genom 7. doi:10.3835/ plantgenome2014.03.0010

Tondelli A, Pagani D, Ghafoori IN, Rahimi M, Ataei R, Rizza F, Flavell AJ, Cattivelli L (2014) Allelic variation at Fr-H1/Vrn$\mathrm{H} 1$ and Fr-H2 loci is the main determinant of frost tolerance in spring barley. Env Exp Bot 106:148-155

Trevaskis B, Hemming MN, Peacock WJ, Dennis ES (2006) HvVRN2 responds to daylength, whereas HvVRN1 is regulated by vernalization and developmental status. Plant Physiol 140:1397-1405

Visioni A, Tondelli A, Francia E, Pswarayi A, Malosetti M, Russell J, Thomas W, Waugh R, Pecchioni N, Romagosa I, Comadran J (2013) Genome-wide association mapping of frost tolerance in barley (Hordeum vulgare L.). BMC Genom 14:424

von Zitzewitz J, Szucs P, Dubcovsky J, Yan L, Francia E, Pecchioni N, Casas A, Chen TH, Hayes PM, Skinner JS (2005) Molecular and structural characterization of barley vernalization genes. Plant Mol Biol 59:449-467

von Zitzewitz J, Cuesta-Marcos A, Condon F, Castro AJ, Chao S, Corey A, Filichkin T, Fisk SP, Gutierrez L, Haggard K, Karsai I, Muehlbauer GJ, Smith KP, Veisz O, Hayes PM (2011) The genetics of winterhardiness in barley: perspectives from genomewide association mapping. Plant Genom 4:76-91. doi:10.3835/ plantgenome2010.12.0030

VSN International (2014) GenStat for Windows, 17th edn. VSN International, Hemel Hempstead, UK

Wang S et al (2014) Characterization of polyploid wheat genomic diversity using a high-density 90,000 single nucleotide polymorphism array. Plant Biotechnol J 12:787-796. doi:10.1111/ pbi. 12183

Wight CP, Tinker NA, Kianian SF, Sorrells ME, O'Donoughue LS, Hoffman DL, Groh S, Scoles GJ, Li CD, Webster FH, Phillips RL, Rines HW, Livingston SM, Armstrong KC, Fedak G, Molnar SJ (2003) A molecular marker map in 'Kanota' x 'Ogle' hexaploid oat (Avena spp.) enhanced by additional markers and a robust framework. Genome 46:28-47

Wooten DR, Livingston DP, Holland JB, Marshall DS, Murphy JP (2008) Quantitative Trait Loci and Epistasis for crown freezing tolerance in the 'Kanota' $\times$ 'Ogle' hexaploid oat mapping population. Crop Sci 48:149

Yan L, Loukoianov A, Blechl A, Tranquilli G, Ramakrishna W, SanMiguel P, Bennetzen JL, Echenique V, Dubcovsky J (2004) The wheat VRN2 gene is a flowering repressor down-regulated by vernalization. Science 303:1640-1644

Yan L, Fu D, Li C, Blechl A, Tranquilli G, Bonafede M, Sanchez A, Valarik M, Yasuda S, Dubcovsky J (2006) The wheat and barley vernalization gene VRN3 is an orthologue of FT. Proc Natl Acad Sci USA 103:19581-19586

Zhu J, Pearce S, Burke A, See DR, Skinner DZ, Dubcovsky J, Garland-Campbell K (2014) Copy number and haplotype variation at the VRN-A1 and central FR-A2 loci are associated with frost tolerance in hexaploid wheat. Theor Appl Genet 127:1183-1197 